\title{
(4) Etiology of Autoimmune Disease
}

\section{Etiological Analysis and Complication of Hashimoto's Thyroiditis}

\author{
Yukio Ochi, Katsuhiko Shiomi, Manabu Yoshimura and Akito KATsuki \\ The Second Department of Internal Medicine, \\ Kyoto Prefectural University of Medicine, Kyoto, Japan
}

As the etiologic factor to induce autoimmune diseases, the abnormality of antigen (abnormal antigen) or the abnormality of antibody-forming system has been focused. By trigger mechanism (inflammation, trauma, virus infection, etc.), the abnormal antigen can be supposed to acquire antigenicity to induce abnormal antibody formation. On the other hand, as the abnormality of antibody forming system, the hereditary constitution (a genetic defect), the mutation of immune competent cells and the prolonged immunization have been postulated.

The present paper describes the hypothesis of general etiology of autoimmune disease through the clinical manifestations and complications of Hashimoto's thyroiditis and through the experimental thyroiditis.

(1) Clinical manifestation and autoantibody of Hashimoto's thyroiditis

Hashimoto's disease has a high familial incidence and often occurs in middleage women. In Hashimoto's disease, anti-thyroglobulin antibody (TRC-antibody and precipitating antibody) and anti-microsome antibody are found frequently and also the antibody titers are extremely high. However, in other thyroidal diseases (hyperthyroidism, hypothyroidism, thyroid cancer, simple goiter and non-toxic nodular goiter), both antibodies are found less frequently and also antibody titers are very low.

(2) Possible role of denaturated thyroglobulin (TG) to induce Hashimoto's thyroiditis

Hashimoto's thyroiditis is believed to be one kind of autoimmune disease producing the antibody against $\mathrm{TG}$, because $\mathrm{TG}$ that is sequestered into thyroid follicle during embryonal period, happens to be released from the thyroid gland after the birth.

Lately, we found the phenomenon of abnormal thyroid hormone ( $\mathrm{T}_{4}$ (thyroxine) and $\mathrm{T}_{3}$ (triiodothyronine)) binding in the $\gamma$-globulin region in the patients of Hashimoto's thyroiditis, that can be explained for the release of denaturated TG from the thyroid gland ${ }^{1}$. In this case, a high binding of $T_{4}$ and $T_{3}$ in the $\gamma$-globulin region was observed by paper and cellulose electrophoresis (Fig. 1). By the absorption of patient sera with TG prior to electrophoresis, the binding of thyroid hormone decreased remarkably. Under the continuous treatment of the patient with prednisolone, the binding in the $\gamma$-globulin region was diminished gradually in associ- 


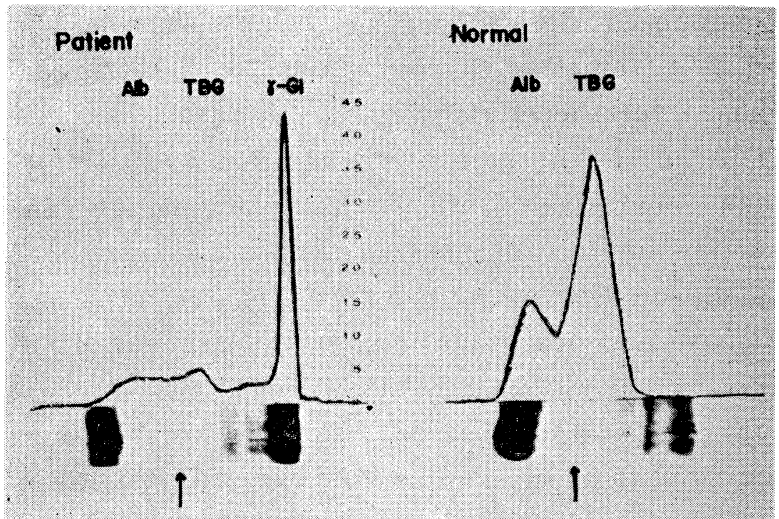

Fig. 1. Distribution of $\mathrm{L}_{-}-\mathrm{T}_{4}{ }^{131}$ in the serum. Cellulose acetate electrophoresis in veronal buffer $\mathrm{pH} 8.6 \mu=0.06$. ation with the decrease of thyroidal antibody.

It has been already reported that such abnormal binding of thyroid hormone in the $\gamma$-globulin region was observed by Robbins ${ }^{2)}$ (thyroid cancer), Premachandra ${ }^{3 \text {, }}$ Roitt $^{4)}$ and Mertz ${ }^{5)}$ (Hashimoto's thyroiditis). Also, the similar findings in the experimental animals have been reported by Premachandra ${ }^{6 / 7) 12)}$, Singh ${ }^{8)}$, McKenzie $^{9)}$, Medda $^{10)}$, Margherita ${ }^{11}$, Pogoriler ${ }^{13)}$, Beal1 ${ }^{14)}$ and Chopra ${ }^{15)}$.

In our clinic, such abnormal

binding was observed in 6 patients of Hashimoto's disease.

To examine the casual factor to evoke the phenomenon, the experimental Hashimoto's thyroiditis was produced in rabbits. In 15 experimental rabbits immunized with native TG (untreated TG), such abnormal binding of thyroid hormone in the $\gamma$-globulin region was not demonstrated. However, such abnormal binding was observed in all of rabbits immunized against denaturated TG by heat $\left(70^{\circ} \mathrm{C}\right.$ for $20 \mathrm{~min}$ or $70^{\circ} \mathrm{C}$ for $10 \mathrm{~min}$ ) and acid- and alkali-treatment with histological changes in the thyroid gland which can resembly be seen in Hashimoto's disease (Table 1).

From these findings, it seems that the antibody formation against thyronine structure that may act as hapten, becomes to be easy by denaturation of $\mathrm{TG}$.

Table 1. Thyroid Hormone Binding Antibody in Immunized Rabbit Against Denaturated Thyroglogulin (TG)

\begin{tabular}{|c|c|c|}
\hline \multirow{2}{*}{$\begin{array}{c}\text { Antigen } \\
\text { Human TG }\end{array}$} & $\begin{array}{c}|c| \\
\text { Antibody for TG } \\
\text { Prith untreated } \\
\text { TG }\end{array}$ & $\frac{\mathrm{T}_{4} \& \mathrm{~T}_{3} \text { binding antibodies }}{\text { Immunized rabbits }}$ \\
\hline Untreated & + & $\frac{0}{15}$ \\
\hline $70^{\circ} \mathrm{C} 20 \mathrm{~min}$ & + & $\frac{4}{4}$ \\
$70^{\circ} \mathrm{C} 10 \mathrm{~min}$ & + & $\frac{4}{4}$ \\
\hline Acid-treated & + & $\frac{2}{2}$ \\
\hline Alkali-treated & + & $\frac{2}{2}$ \\
\hline
\end{tabular}


From these observations, it is also supposed that in some cases of Hashimoto's thyroiditis the release of denaturated TG from the thyroid gland by the trigger mechanism may be very important factor for the etiology of the disease.

As the denaturation of IgG or DNA as the antigen of rheumatoid arthritis or systemic lupus erythematodes has been demonstrated, the similar phenomenon can be proved to be the etiology of some Hashimoto's diseases.

(3) Complications of Hashimoto's thyroiditis and lupoid hepatitis.

The coexistenceof Hashimoto's disease and other autoimmune disease has often been seen.

The present paper describes the complicated case of hepato-thyroidal autoimmune disease. The patient had the symptoms of Hashimoto's thyroiditis with a high titer of anti-thyroid antibody (TRC $>10^{24}, \mathrm{MCF}>320$ ) and increased $\gamma$-globulin $(6.6 \mathrm{~g} \%)$ at the time when no liver damage was observed. By the electrophoresis using cellulose acetate membrane, the wavy band was seen in the $\gamma$-globulin region that was proved as polyclonal by the immunoelectrophoresis. Two years later, the patient became subicteric and revealed enlargement of the liver and the spleen and also palmar erythema. In the laboratory data, LE phenomenon, RA and Coomb's direct were positive. The autoimmune mechanism was supposed as the etiological factor from the histologic changes in the liver and thyroid. Although the $\mathrm{Au}$ antigen was negative, the Au antibody was positive in the patient serum during 3 years (Fig. 2).

Generally, in Hashimoto's thyroiditis the complication with various other autoimmune diseases and also many auto-antibodies are found frequently, therefore the specific genetic factor is postulated as the etiology of autoimmune diseases. If one kind of autoimmune disease is continued by the abnormal antigen as etiologic factor, it is also possible to suppose that other immune diseases may be complicated by the prolonged immunization and the long standing sensitization.

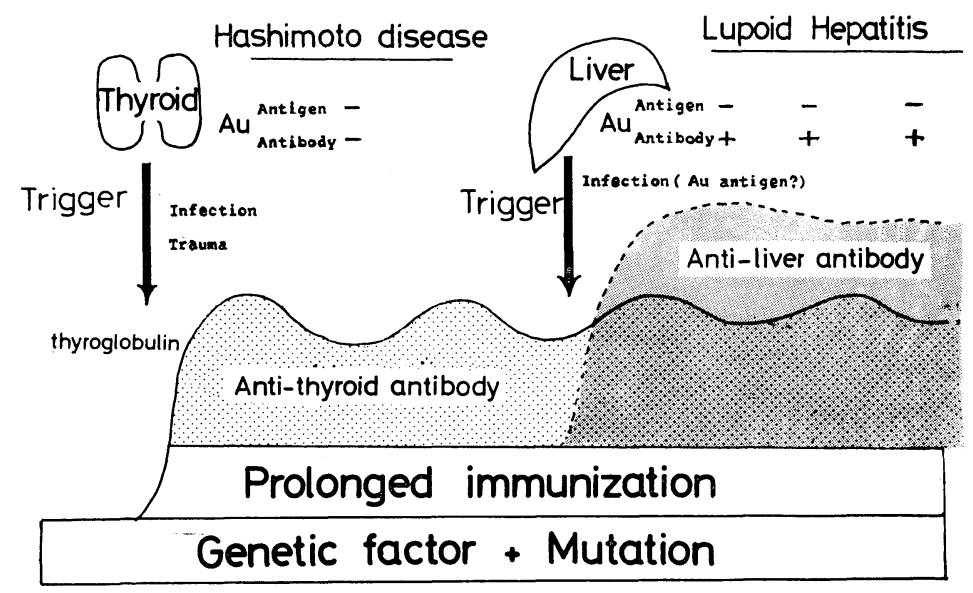

Fig. 2 


\section{References}

1) Shiomi, K., Hachiya, T., Abe, S. and Ochi, Y.: Hormone to Rinsho, 19: 553, 1971.

2) Robbins, J., Rall, J. W. and Rawson, R. W.: J. Clin. Endocrinol. 16: 573, 1956.

3) Premachandra, B. N. and Blumenthal, H. T.: ibid. 27:931, 1967.

4) Roitt, I. M., Torrigiani, G. and Doniach, D*: Immunology 15:681, 1968.

5) Mertz, D. S., Stelzen, M. and Meigen, B.: Medische Welt, Ber1 9: 423, 1968.

6) Premachandra, B. N., Ray, A. K. and Blumenthal, H. T.: Proc. Soc. Exp. Biol. Med. 110: 277, 1962.

7) Premachandra, B. N., Ray, A. K., Hirata, Y. and Blumenthal: Endocrinology 73: 135, 1963.

8) Singh, K. D. and Premachandra, B. N.: Fed. Proc. $24: 242,1965$ (Abstract).

9) McKenzie, J. M. and Haibach, H.: Endocrinology 80: 1097, 1967.

10) Medda, A. K. and Premachandra, B. N.: Acta Endocr. (Copenh.) 59: 159, 1968.

11) Margherita, S. S. and Premachandra, B. N.: J. Immunology 102: 1511, 1969.

12) Premachandra, B. N.: Endocrinology 86: 703, 1970.

13) Pogoriler, G., van Maanen, J.H. and Sellers, E. S.: Acta Endocrinol. 50: 547, 1971.

14) Beall, G. N., Solomon, D. H. and Chopra, I. J.: Proc. Soc. Exp. Biol. Med. 138: 525, 1971.

15) Chopra, I. J., Nelson, J. C., Solomon, D. H. and Beall, G. N. : J. Clin. Endocrinol. 32 : 299 , 1971. 